McCabe, W. R. \& Jackson, G. C. (1963). Arch. Int. Med., I I0, 847.

Mitchell, R. G. (1965). Brit. med. F., I, I I 27.

Silver, J. R. (I968). Paraplegia, 5, No. 4, 226.

ThOMPSON WALKer, J. (I937). Brit. F.Urol., 9, 2 I 7.

Tribe, C. R. \& Silver, J. R. (I969). Renal Failure in Paraplegia. London: Pitman.

Waisbren, B. A. (1964). Amer. Fournal of Med., 36, No. 6, 819.

Weil, M. H., Shubin, H. \& Biddle, M. (1964). Annal of Int. Med., 6o, 384.

\title{
Discussion
}

Chairman (Dr. T. GREGG). We are used to expecting something special from Southport, and Dr. Silver has certainly lived up to it. We have gone over time in this particular period, and perhaps if anyone has any detailed points they could speak to Dr. Silver afterwards. If there are any points of general interest or any questions anyone would like to ask now, if they could be very brief, Dr. Silver has to leave in five minutes. The paper will be published and it was very comprehensive, and thanks are due to you, Dr. Silver.

\section{THE SPINAL UNIT AT MURNAU (GERMANY)}

\author{
By Dr. E. Stophasius
}

IF you look at the first slide, don't be afraid that I am going to hold a paper on agriculture or that I wish to make advertisement for Bavarian milk-I would just like to give you a general view at the new Spinal Centre at Murnau.

This year, on 24 January, the Centre of the Accident Hospital at Murnau was opened in the presence of Sir Ludwig. It has to be mentioned that it was Sir Ludwig who stimulated the German authorities to attach a Spinal Centre to the Murnau Accident Hospital (Berufsgenossenschaftliches Unfallkrankenhaus), which has been directed until 3I January I969 for almost I5 years by Professor Dr.med. A. Lob, who planned the new Unit and supervised the construction of it.

The Hospital as well as the Centre itself is run by a union of several so-called Berufsgenossenschaften-that are Employers' Liability Insurance Associations, which are compulsory. The insurance premium is paid exclusively by the employer.

The capacity of the centre is 60 beds in three wards of 20 beds. Each ward consists of 2 four-bed rooms and 6 two-bed rooms located in the south of this fivefloor building. They are connected by three balconies. To each room belongs a sanitary unit, 4 patients. sharing one toilet. Each room is connected to the central oxygen and air pressure supply system as well as to an optical and acoustic call system.

In the north of each ward are located the functional rooms divided from the bedrooms by a wide floor.

In the east of the wards are the eating and sitting rooms and the elevators.

The floor below the wards is occupied by the occupational therapy department, including a kitchen for training of paraplegic women; dressing-rooms for the personnel and an office.

The operating theatre, the X-ray department, the laboratories, the central sterilisation, the urological theatre and the rooms for the consulting specialists are at the next lower floor.

At the same floor southwards in another complex there is the physiotherapy 
PAPERS READ AT THE I 969 SCIENTIFIC MEETING

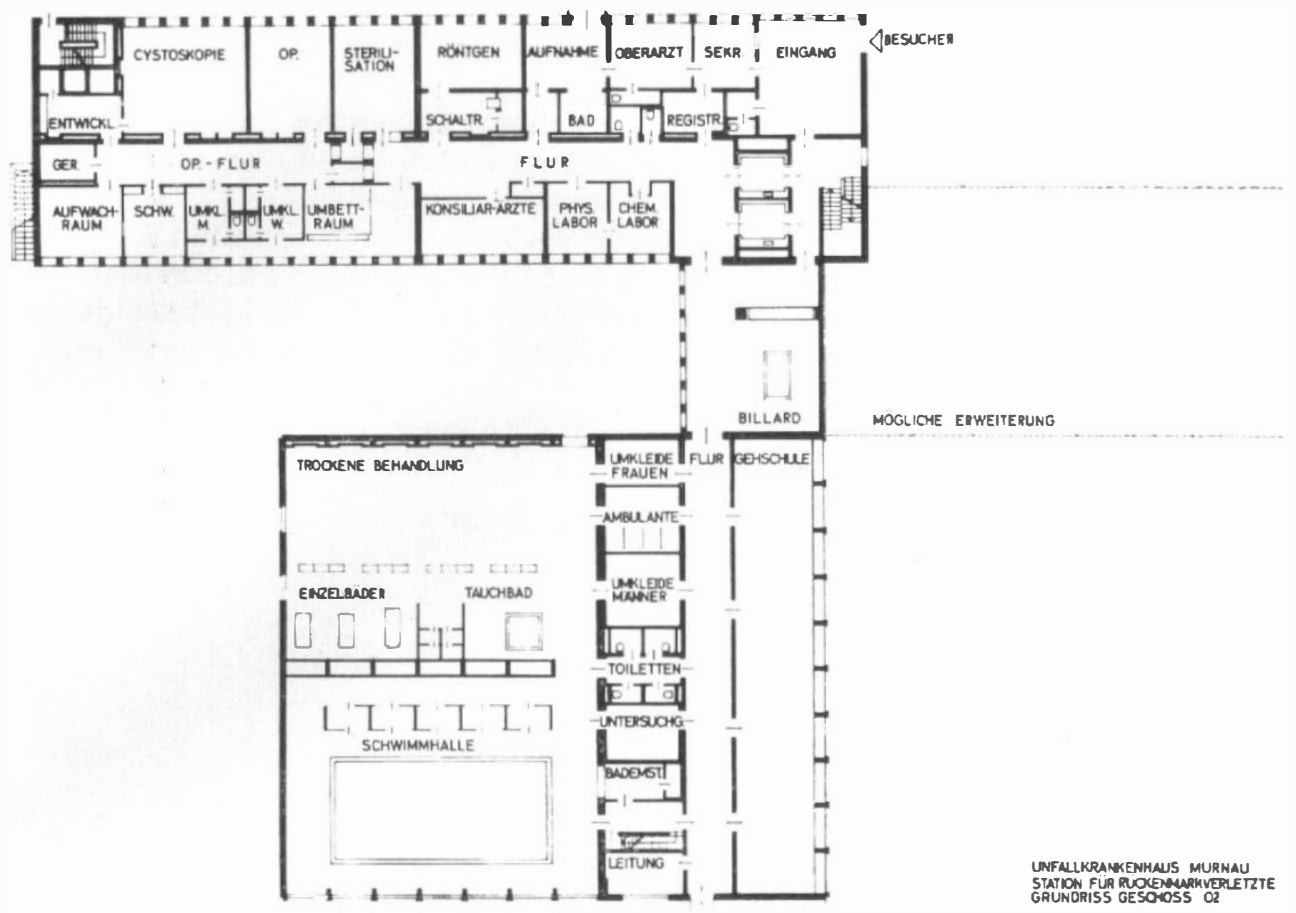

FIG. I

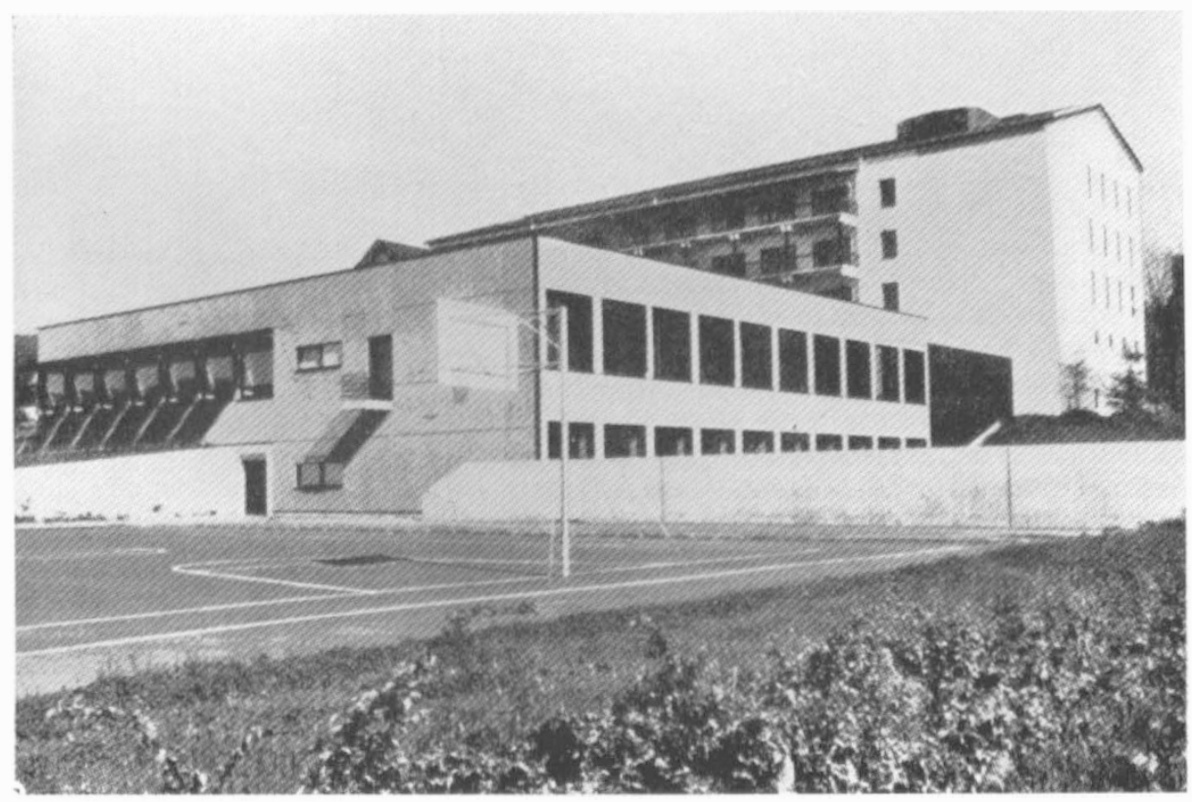

FIG. 2 
department and the swimming-pool. One floor below one can find the gymnasium and the central bed supply. The costs of the Spinal Centre itself run up to approximately DM I4.000.000,- .

From I3 June to I6 June 1969 the 4 th National Games for Paraplegics took place at Murnau. One hundred and forty competitors from all over the Federal Republic were brought in by army helicopters and aeroplanes.

Murnau is located in Upper Bavaria near Garmisch-Partenkirchen. We shall be glad to welcome everybody as our guest, to get criticism and advice in order to become not only the youngest Spinal Centre but to live up to the high standards set up by Sir Ludwig and his scholars. Still much has to be done for paraplegics in Germany.

Figures I and 2 demonstrate the layout of the Centre. 